\title{
Jorge, Enrique, seus personagens
}

\author{
Jorge, Enrique and their characters
}

Reginaldo da Luz Pujol Filho

Pontifícia Universidade Católica do Rio Grande do Sul - Porto Alegre, RS, Brasil

$\diamond$

\begin{abstract}
Resumo: Estre trabalho assume seu risco formal assim como o fizeram os autores que o ensejam, Jorge Luis Borges e Enrique Vila-Matas. Podemos dizer que apresentamos uma hipótese fantástica à moda de Borges de Tlon, Uqbar Orbis Tertius ${ }^{1}$ e outros contos seus. Quer dizer, propomos relações e proximidades entre Borges e Vila-Matas e o catalão como continuador do argentino, com as ferramentas dos dois: a ficção e o fantástico. O que nos aproxima do outro autor aqui relacionado. Se Vila-Matas já disse que "minha voz é de um ensaísta que utiliza narração como suporte do ensaio" 2 , nada mais justo que ensaiar sobre ele utilizando a narração. Assim acreditamos refletir sobre entrelaçamentos possíveis entre os autores; a questão da autoria; a questão pós-moderna da apropriação, da citação, do eco. Arriscando na forma, como os dois autores.
\end{abstract}

Palavras-chave: Enrique Vila-Matas; Jorge Luis Borges; Apropriação; Autoria; Escrita criativa

\begin{abstract}
This work assumes the risk as a form, in the same way that the authores who inpired this piece (Jorge Luis Borges and Enrique Vila-Matas) did. In some way, we can say that we are presenting a fantastic hipothesis in the same style os much of the Borges' short stories, like Tlon, Uqbar Orbis Tertius. It means: we evoke the fiction and the fantastic to think about the relationship between the work of Borges and the work ofo Vila-Matas. Something that approach us from the other author mentioned here. If Enrique Vila-Matas already said that "My voice is from an essayist who uses narration as a support of the essay", it's totally fair to use the narration to make a esay about him. So we beliave that this work makes a reflexion about the possible interlacements nettween thos two authors; the issue of authorship; the issue of the postmoden appropriation. And to reach this, we assume the risk as a form.
\end{abstract}

Keywords: Enrique Vila-Matas; Jorge Luis Borges; Appropriation; Autorship; Creative writing

1

$\mathrm{Na}$ entrada do apartamento, Enrique bate os pés sobre o capacho, entra, fecha a porta mais encostando do que batendo, quase silenciosamente. Larga o blazer no cabide, com as costas da mão enxuga uma ou duas gotas de suor da testa.

\footnotetext{
1 VILA-MATAS, Enrique. [10 de fevereiro de 2017]. Enrique Vila-Matas: "Aunque no lo quiera, la literatura invade mi vida". Disponível em: $<$ http://www.elcultural.com/revista/letras/Enrique-Vila-Matas-Aunqueno-lo-quiera-la-literatura-invade-mi-vida/39209>. Acesso em: $30 \mathrm{abr}$. 2017 (tradução nossa).

2 VILA-MATAS, Enrique. [10 de fevereiro de 2017]. Enrique Vila-Matas: "Aunque no lo quiera, la literatura invade mi vida". Disponível em: $<$ http://www.elcultural.com/revista/letras/Enrique-Vila-Matas-Aunqueno-lo-quiera-la-literatura-invade-mi-vida/39209>. Acesso em: 30 abr. 2017 (tradução nossa).
}

- Que calor - ele reclama baixo. Passa os olhos pelo ambiente todo escuro, avança para a sala sem acender as luzes, deixa a sacola da Bernat sobre a poltrona. Contorna a mesa e vai até a cozinha, e seu rosto cansado fica agora mais visível com a luz da geladeira, marcando rugas, cavidades sob os olhos. Com uma das mãos, tenta alisar os amassados que o dia suarento deixou na sua expressão. Da sala, vem o zumbido do motorzinho em volume crescente e, então, o som de batida, talvez do ombro, talvez de uma roda, certamente contra algum móvel. É provável que a vítima do atropelamento tenha sido a mesinha que forma uma perigosa esquina a ser dobrada por quem vem dos quartos. Enrique olha para a entrada cozinha. A porta da geladeira ainda aberta é o holofote que ilumina a entrada em cena do velho cego, pilotando sua cadeira de rodas 
elétrica. O velho estaciona sob o marco da porta e é como se olhasse:

- Então, Enrique.

- Buenas, Jorge.

- Como foi com o jornalista português?

- A mesma coisa de sempre.

- E o que isso quer dizer?

Enrique fecha a geladeira, quem sabe preocupado com a conta de luz, ou por democracia, se um não pode ver por que o outro merece o privilégio? Abre uma lata de Coca-cola. O velho arregala os olhos que não veem.

- Ah, Jorge. Que sei eu. A mesma coisa de sempre. As mesmas perguntas, o que é verdade e o que ficção no livro novo, o que há de ensaio, e sobre Dylan, e sobre o congresso do,

- Mal sabem eles.

Enrique faz um pois é com a cabeça.

- Ah, sim, Jorge. Talvez te agrade isso: o português também perguntou o que eu quis dizer com a frase Quando escurece, sempre precisamos de alguém.

- E o que você disse?

Enrique olha para a lata de Coca-cola. Não chega a tomar um gole.

- Não lembro. Qualquer coisa. Mas fiquei com vontade de te perguntar: essa frase é tua: se referia à falta de visão, ao nosso trabalho, à literatura? Fiquei curioso também.

- Que sei eu, Enrique? Você sabe o que querem dizer todas as suas frases? Os McGuffins? Já foram tantas.

Enrique dá uns passos passando ao redor da cadeira; o velho, feito um sonar, acompanha a passagem girando a cabeça, conduzido pelo ruído dos sapatos raspando o carpete.

- Mas, Jorge, às vezes penso: acha que um dia eles saberão que a gente, digo, tudo isso?

- Ah, não me ocupo disso, chico. E se souberem, quiçá as coisas fiquem ainda melhores, não? Não sei. Na verdade, tenho me divertido tanto e isso já me basta.

Enrique sorri, mas só Enrique sabe disso.

- É, é divertido. Mas tem momentos em que, não sei, me inquieto com toda essa minha atuação, tu aqui há tanto tempo. Veja, penso se não é um pouco medíocre a minha condição, essa encenação sempre que saio deste apartamento, atendo o telefone, respondo e-mails. Nem sei mais se sou tão Enrique, se sou Jorge, se sou alguém, quantos livros já escrevemos, quantos contos? Não ria, Jorge, estou vendo teu sorriso. É muito cômodo ficar aqui, ditando, trocando ideias, mas eu, digo, se eu parar de me esconder atrás de tantos textos, seria capaz de dizer algo sobre mim?

- Se eu pudesse, saía dos bastidores e te dava uma folga, assumia a linha de frente.
Enrique, na escuridão, talvez veja o cego fazer movimentos de quem olha para as próprias pernas (ou o que devem ter sido pernas há uns bons anos) desarticuladamente dissolvidas debaixo da manta, sobre o assento da cadeira de rodas.

- Não quis dizer isso, Jorge. Calma lá. Vem cá, vamos, quer comer alguma coisa?

- Não estou com fome.

- Não faz assim.

- É verdade.

- Bom, eu vou comer algo na sala.

Carregando pratos, um pacote de pão, a lata de refrigerante e alguns fiambres, Enrique deixa a cozinha. É perseguido pelo som do motorzinho. Ele vira-se para trás e vê aquele personagem um pouco obscuro, o seguindo como uma sombra.

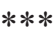

\section{2}

Mastiga um pão com chorizo e olha para o velho no canto mais escuro da sala. Pode estar dormindo, pode estar escrevendo, sofrendo até, sempre difícil saber.

- Jorge.

- Sim

- Pensei que estava dormindo.

- Não, eu,

- Hoje perguntaram de novo sobre as frases.

- Que frases?

- As frases, ora, como dizia Nietzsche, como dizia Borges, querem sempre saber o que,

- Como dizia Borges, essas são bárbaras, adoro quando fazemos isso - o velho bate uma palma quase silenciosa - me ocorre que você poderia dizer um dia em uma conferência, ou podemos botar no próximo livro, Uma vez, Borges citando Hegel, disse que,

- E será verdade?

$\mathrm{O}$ velho não responde.

- Sim, Escrever é tentarmos escrever o que escreveríamos se escrevêssemos.

- Marguerite Duras!

O velho termina de falar e sorri feito um velho normal que ouvisse seu número definitivo no bingo.

- Também falei sobre essa hoje com o português. Acabei revelando o jogo para ele. Pode isso? O sujeito ainda acreditava na frase. O livro saiu quando? Em 2000? Vá lá, dois mil e pico em Portugal. Mas já estamos em 2012 e o tipo ainda crê? Não é estranho? Ah é. E hoje também empurrei para ele uma história, uma história de que eu teria me apropriado de uma frase de Shakespeare. Ele adorou. 
- Enrique, veja aí, vamos, veja aí na internet com quantas citações anda a nossa prestigiosa Marguerite Duras.

- Antes deixa eu terminar o jantar.

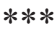

\section{3}

- Mil setecentas e sete ocorrências, Jorge.

- Isso é bom ou ruim?

- Não sei. Temos frases com mais citações e há os contos que circulam feito praga na rede. Não sei avaliar.

- Exisem livros que saem com menos exemplares do que isso. Meu primeiro livro teve trezentos exemplares, não me lembro de já te contei isso, chico.

- Mas nossos livros têm saído com edições um pouquinho maiores, você sabe - Enrique olha para o lado e vê um quase sorriso de orgulho na máscara de rugas que faz as vezes de rosto do seu companheiro Mas vou dormir, meu caro.

- Não, Enrique. Vamos.

Enrique vê o velho apontar, com o queixo e os olhos cegos, a mesa de trabalho.

- Ah, Jorge,

- Precisamos escrever um pouco mais hoje.

- Não, estou morto, preciso deitar. A Bernat anda insuportável, autógrafos e perguntas e fotos. E turistas literários, onde já se viu? Que ideia essa de meter a livraria naquele livro. Ah, que lindo, uma livraria na Calle Buenos Aires, que charada simpática. Que queremos? Que nos descubram ou não? Ou o quê? Sentirmo-nos superiores com os enigmas que só nós deciframos?

- A ideia da Bernat foi sua.

- Foi? Já não me lembro.

Enrique apoia-se na mesa do computador e levantase da cadeira, mas o velho, como se enxergasse os movimentos, agarra o pulso do amigo com uma força impossível:

- Enrique, pensei que fosse isso que você queria. Lembra, quando nos conhecemos em Genebra, era o quê, $1983,1984 \ldots$ aquelas suas frases sobre ser um ladrão de frases alheias, sobre ter sido um parasita em relação aos seus escritores mais admirados e querer transformar isso em estilo, embaralhar o literário. Embaralhar o literário. Ah, falei para Maria naquela autura que eu havia encontrado meu parceiro, que tínhamos um grande futuro. E acho que tivemos, não?

Em pé, Enrique mira o olhar, se é que possível, ainda mais perdido do velho. Faz que não com a cabeça.

- Mas esse teu apego a tudo o que eu disse. Sim, eu sei que disse isso, alguém fez questão de meter no meio do Mal, no meio do romance, para eu não me esquecer. E não nego, Jorge, foi a vida que escolhi, que escolhemos. Estamos nessa história até o fim. Não sou moleque. Mas é tarde, não posso fazer isso vinte e quatro horas, eu passei o dia em entrevistas e, ah, preciso,

- Ah, é preciso escrever sempre, escrever amanhã $e$ depois de amanhã, escrever em Paraty e escrever em Barcelona, escrever,

E o velho interrompe a frase, engasgado numa risada asmática e milenar. Enrique coça a testa avantajada, com pressão quase agressiva, alisa para trás os cabelos que restam. Olha para o velho que ainda luta com sua risada.

- Essa frase é tua, Jorge.

- Como muitas outras. Mas não assino colunas com ela no El País, nem a li em Para, lá no Brasil, para delírio de fãs. Não vi o vídeo, Enrique, mas escutei os aplausos. Está cansado disso? Precisa descansar disso? Vai me dizer que não gosta dos aplausos, dos autógrafos?

Enrique faz que não com a cabeça, o velho obviamente não vê sua contrariedade, nem o vê falsear um passo que não chega a dar. Ele para ao receber no pulso o toque quase não-toque de tão fraco da mão de osso e pele que pesa talvez miligramas, mas ainda assim o ancora ali, em pé, olhando para baixo, paro o velho que não direciona a cabeça para ele. Apenas a mão em frágil contato.

- Mas escrever o quê, Jorge?

- Elaborei mais um capítulo hoje enquanto você dava a entrevista para a revista Ler. Vamos, é preciso,

- Escrever, escrever, escrever?

- Não, Enrique. É preciso lançar mais livros. Embaralhar mais cartas, mais páginas, o jogo não pode parar.

Enrique faz uma volta pelo escritório, apoia-se no encosto da cadeira vazia.

- E depois pensar nas respostas para entrevistas, elaborar conferências e,

- Diga: quer sair dessa?

- Mesmo que eu quisesse, 30 anos depois seria como tentar sair de um labirinto.

Ele senta-se na cadeira em frente ao computador e vê o velho friccionar as mãos nos dois sacos de pele que ele ainda pensa serem pernas. Frio ou prazer, Enrique não tem como saber.

- Chistes com labirintos, Enrique. Sei que você pode mais. Mas, vejas, pensei também em um textinho curto, tenho saudade de contos, da digressão oral e, bem, pensei em conto com a seguinte premissa: escritores com a Síndrome de Menárd.

Enrique prende o ar na garganta, como se guardasse fôlego para o resto da noite, ou da vida. 


\section{4}

Enrique esfrega os olhos com as duas mãos, o ambiente está mais claro, algo de sol passa pelas venezianas. Olha para o velho:

- Pronto, Jorge. Terminamos. Mas esse não é para o livro, é?

- Esse podemos jogar na rede, como você me disse que falam os jovens. Assinamos como Ernest Hemingway, que acha? Ou como aquele brasileiro, o tal do Verissimo? O que acha, Enrique?

- Não sei, Jorge. Escolhe tu, por mim está bem.

O velho fricciona os braços da cadeira de roda, excitado. Enrique observa aquele gestual infantil.

- Esse nome do brasileiro tem funcionado muito bem, não, Enrique? Quantas ocorrências tivemos do último texto que assinamos com o nome dele.

- Não lembro, Jorge. Que tal decidirmos essa parte amanhã? Precisamos dormir, hoje eu tenho que,

- Quando chegar na minha idade, você vai ver que se dorme muito menos.

- Ah, acho que não chego aos 113, meu caro, Jorge. Nem sei se quero ir tão longe.

- 114 amanhã.

- Vou ter que te comprar um presente. A Maria vem?

- Ah, aquelas chatices de homenagens na fundação. Ela deve vir no domingo.

- Então, pronto, vamos dormir. Amanhã o aniversariante tem que estar bem.

- Eu estou. E vou ficar melhor se a gente agora terminar aquele capítulo do romance.

- Mas, Jorge, amanhã eu tenho que, lá na Bernat.

- Pelo meu aniversário, Enrique. Para eu dormir com a cabeça um pouco mais descansada.

Enrique toma um gole de água. Olha para a tela do computador. Olha para o velho como se tentasse encontrar algum sinal de sono escondido entre aquele amontoado de rugas.

- Posso fazer só uma pergunta antes?

- E eu posso mentir a resposta?

De algum lugar, Enrique saca um sorriso, tenta rir como se fosse para o velho perceber que ele ainda aprecia o seu humor.
- Anda, pergunte, chico.

- Tu e o Adolfo,

- Que tem? Faz tanto tempo.

- Nada. Só, eu às vezes fico imaginando se, como posso dizer. Ah, deixa.

- Deixa o quê, chico? Fala

- Não, o ponto é, digamos, quando vocês, se nos projetos de vocês dois, se tinham em mente fazer algo como que nós estamos fazendo aqui, agora, há tantos anos. Digo, essa era uma ideia de vocês que não pode ser levada adiante?

- Não, Enrique, não. Adolfo não gostava desses jogos. Nunca fomos tão longe. Não, não fomos tão longe.

Enrique confirma com a cabeça, abre um novo arquivo no computador.

\section{Referências}

BORGES, Jorge. Fiç̧ões. Trad. Carlos Nejar. Porto Alegre: Globo, 1970.

PIGLIA, Ricardo. Novas teses sobre o conto. In: PIGLIA, Ricardo. Formas breves. São Paulo: Companhia das Letras, 2004. p. 95-114.

REVISTA LER. Enrique Vila-Matas: "Se me dessem o Nobel, eu recusava" (entrevista). Lisboa, abr. 2012. p. 66-72.

VILA-MATAS, Enrique. Bartleby e companhia. São Paulo: Cosac Naify, 2004.

VILA-MATAS, Enrique. O mal de Montano. São Paulo: Cosac Naify, 2005.

VILA-MATAS, Enrique. Doutor Pasavento. São Paulo: Cosac Naify, 2005.

VILA-MATAS, Enrique. História abreviada da literatura portátil. São Paulo: Cosac Naify, 2013.

VILA-MATAS, Enrique. [10 de fevereiro de 2017]. Enrique Vila-Matas: "Aunque no lo quiera, la literatura invade mi vida". Disponível em: <http://www.elcultural.com/revista/letras/ Enrique-Vila-Matas-Aunque-no-lo-quiera-la-literatura-invademi-vida/39209>. Acesso em: 30 abr. 2017 (tradução nossa).

Recebido: 30 de abril de 2017

Aprovado: 01 de julho de 2017

Contato:

Reginaldo da Luz Pujol Filho <reginaldo_pujol@yahoo.com.br> 